\title{
Fuentes y proyección de las causales de incapacidad*
}

\author{
Sources and forecast of legal \\ incompetence's causes
}

\section{Alejandro Lajel}

${ }^{1}$ Universidad Abierta Interamericana. Argentina.

alejandro.laje@uai.edu.ar

\section{Gabriel E. Lanzavechia ${ }^{2}$}

${ }^{2}$ Universidad Abierta Interamericana. Argentina.

gabriel.lanzavechia@uai.edu.ar

https://doi.org/10.22235/rd.v0i17.1520

ReSUmen: El presente trabajo analiza la evolución del concepto de las categorías jurídicas persona, capacidad e incapacidad con el fin de hacer una proyección de la evolución de las causales de incapacidad en el derecho, tomando como criterio la legislación de la República Argentina. Se describen las fuentes de estos institutos y su validez a la luz del principio general de solidaridad jurídica.

Palabras clave: incapacidad, causales, validez, solidaridad.

Recibido: 18/12/17. Evaluado: 15/2/18. Aceptado: 21/2/18

* Este trabajo es resultado parcial del Proyecto de Investigación titulado "Indagación y Análisis de las Fuentes del Código Civil y Comercial Argentino”, dirigido por Alejandro Laje y por Lucila I. Córdoba, radicado en el Centro de Altos Estudios en Ciencias Sociales de la Universidad Abierta Interamericana. 
ABSTRACT: This work analyses the evolution of the concepts of person, legal competence and incompetence in order to assay a forecast of the evolution of the causes of legal incompetence. It works with the law of the Argentine Republic as reference. The sources and validity of the concept of person, legal competence and incompetence are described taking into account the general principle of legal solidarity.

KEY-WORDS: legal incompetence, causes, validity, solidarity

SUMARIO: 1. La persona humana. 2. El sistema de capacidad en la República Argentina. 3. La evolución de la incapacidad en el derecho argentino. 4. El sistema del Código Civil y Comercial de la Nación. El ámbito interno. Un cambio de rumbo. La incapacidad por inmadurez. La incapacidad por afectación de la voluntad o del entendimiento. 5. Fuentes del sistema de incapacidad del Código Civil y Comercial. 6. Otras fuentes del sistema de incapacidad. 7. Proyección de las causales de incapacidad. 8. Conclusiones. 


\section{LA PERSONA HUMANA}

El derecho argentino en la Constitución Nacional, los tratados internacionales, la normativa específica del Código Civil y Comercial de la Nación (CCC) y otras leyes particulares coloca a la persona humana en el centro de la consideración jurídica. Esta valoración merece ser analizada con detenimiento.

La noción de persona se vincula con la de sujeto y, si bien son utilizadas frecuentemente como sinónimos, no lo son.

Es sabido que fueron" los romanos quienes desarrollaron primero el concepto de persona. Gallo lo identificó con el aspecto biológico, hombre-físico, libre o esclavo: "Et quidem summa divisio de iure personaurm haec est, quod omnes homines aut liberi sunt aut serui", la división más general del derecho de las personas es esta: los hombres son libres o esclavos. ${ }^{1}$ Interesante consideración que habilitaba ya la posibilidad de que no toda persona fuera sujeto de derecho, aunque sí que todo sujeto de derecho fuera persona. Ello derivó en una noción que denota principalmente la habilitación que recibe la persona para ejercer ciertos roles y capacidades en la sociedad. Ser persona quiere decir ser reconocido por los demás en dicho rol y capacidad.

El origen epistemológico de la palabra sujeto se refiere a lo que existe en sí y no en otro. Asimismo, el término sujeto designa, en una proposición o juicio, lo determinado por otro elemento, pues el sujeto en tanto que sujeto del juicio es lo indeterminado. ${ }^{2}$ La noción de persona, en cambio, no se corresponde con la idea de sujeto de la predicación sino en predicado, como relación de determinación, capacidad de acción y relación intersubjetiva.

La alta noción de persona que tenemos en la actualidad determinó que su voluntad, su autonomía y en definitiva su libertad sean el estándar de su condición. Tener un derecho

\footnotetext{
1 Gallo, Institutas, Commentarius Primus III. De conditione hominum, http://fama2.us.es/fde/ocr/2006/ institutaDeGayo.pdf, 1.2.2018.

2 Cf. Jacinto Choza , Filosofía del Hombre, (Madrid: Ediciones RIALP, 1993), 427 y ss.
} 
significa tener derecho a que se respete la voluntad de la persona que, además, debe poder ser exteriorizada.

La idea actual de persona humana como sujeto de derecho abreva entonces de ideas metafísicas y jurídicas. De las primeras se deduce que todo ser humano es persona, sin admitir restricción alguna. De las segundas se concluye que es una realidad relacional, por lo que su condición y particularmente sus manifestaciones inmediatas, como por ejemplo su intimidad, su integridad y su identidad no son algo dado de una vez por todas, sino que requieren desarrollarse, realizarse.

La idea de persona humana como categoría jurídica remite también al concepto de intersubjetividad, al reconocimiento que le da cada sujeto a las capacidades del otro; y en este sentido dicha categoría es necesariamente relacional. De allí que en la actualidad se considere que toda persona humana goza de la aptitud de ser titular de derechos y deberes jurídicos. La ley puede privar o limitar esta capacidad respecto de hechos, simples actos o actos jurídicos determinados, pero no negarla totalmente.

El derecho trabaja con relaciones jurídicas y en consecuencia no toma a la persona humana en toda su integridad ni como un absoluto. ${ }^{3}$ No se refiere a su constitución física o moral como tal y disciplina su conducta en un sistema de principios y reglas que se acomodan a las circunstancias y necesidades que derivan del estándar moral de la sociedad a la que pertenece. Esta regulación está justificada por la idea central del sistema jurídico que considera que la persona se desenvuelve en un ámbito de libertad, donde es su elección la que determina su futura circunstancia, dentro de los efectos que las normas adjudiquen a las conductas deseadas o reprobadas por la ley.

\section{EL SISTEMA DE CAPACIDAD EN LA REPÚBLICA ARGENTINA}

Enseña Alfredo del C. M. Córdoba que la nota incorporada por Vélez Sarsfield al art. 30 del el Código Civil explica que la expresión "capacidad de adquirir derechos" comprende implícitamente cuatro fases: 1) la adquisición en sí del derecho, 2) la duración y ejercicio del mismo, 3) su defensa y conservación y 4) su pérdida total. De allí que la personalidad es la condición jurídica general de los entes que son sujetos de derecho y capacidad es la situación

\footnotetext{
3 Marcos M. Córdoba, "Actualidad del Derecho de Familia" (conferencia, Instituto de Derecho de Familia del Colegio Público de Abogados, Buenos Aires, 2 de octubre de 2017).
} 
particular de personas determinadas, estableciendo su aptitud para ser titulares o sujetos, activos o pasivos de relaciones jurídicas y de ejercer por sí mismos sus derechos subjetivos.

La capacidad es la medida concreta de esa aptitud en personas determinadas, tanto en relación con ciertos derechos o actos jurídicos, como al ejercicio por sí mismas de esos derechos. La capacidad es así un atributo de la personalidad pues no puede concebirse la persona que no sea en algún grado capaz, y la cualidad de capaz no puede predicarse sino respecto a personas y no de objetos o de actos.

Continua el ilustre maestro Alfredo del C. M. Córdoba diciendo que sus caracteres (de la capacidad) son, además de los comunes a todos los atributos de las personas: 1) que es susceptible de grados; que puede ser plena o limitada, 2) que la capacidad es la regla y la incapacidad la excepción, y que ésta solo se admite si es expresa y 3) que las incapacidades no pueden extraerse de otra fuente del derecho que la ley. ${ }^{4}$

La construcción del concepto de capacidad de derecho se basó tradicionalmente en la idea central de su correlación con la titularidad de derechos subjetivos. Sin embargo, Tobías advierte que en la sistematización del Código Civil y Comercial resulta más preciso y comprensivo correlacionar la noción de capacidad de derecho con la aptitud potencial de ser titular de intereses tutelados por el derecho y no solo de derechos, ${ }^{5}$ ya que sería también apropiado hacerlo extensible a derechos, facultades, poderes o deberes que forman parte del contenido de la relación jurídica.

La incapacidad de ejercicio, o sea la falta de aptitud de la persona para ejercer por sí misma derechos o para realizar actos jurídicos es impuesta por la ley a causa de su falta de madurez o por padecer una adicción o una alteración mental permanente o prolongada de suficiente gravedad, siempre que se estime que del ejercicio de su plena capacidad puede resultar un dańo a su persona o a sus bienes. Así se establece con el fin de proteger a la persona, impidiéndole que pueda realizar actos que pudieran perjudicarle.

\footnotetext{
4 Alfredo del C. M. Córdoba, Derecho Civil. Parte General, (Buenos Aires: Biblioteca de la Universidad Abierta Interamericana, 2017), 52-60.

5 José W Tobías, “La persona humana en el proyecto", La Ley, 25/06/2012.
} 


\section{LA EVOLUCIÓN DE LA INCAPACIDAD EN EL DERECHO ARGENTINO}

El Código de Vélez consideraba incapaces absolutos a las personas por nacer, a los menores impúberes, a los dementes, a los sordomudos que no supieran darse a entender por escrito y a los ausentes declarados tales en juicio. Vélez excluyó expresamente a los pródigos, aclarando en la nota al art. 54 que "en el número de los incapaces, no pongo los pródigos porque esa calidad no podrá, según este Código, ni sujetarse a juicio ni traer una interdicción.” En el art. 55 Vélez estableció que los menores adultos y las mujeres casadas eran incapaces respecto de ciertos actos o del modo de ejercerlos.

La Ley 17.711 eliminó de la lista de incapaces a los ausentes declarados tales en juicio y dispuso que los menores adultos sólo tendrían capacidad para los actos que las leyes les autorizan.

La ley 11.357 fue el primer paso tendiente a eliminar la desigualdad jurídica entre el hombre y la mujer, pero en los hechos no significó cambios importantes. No así la ley 17.711 que sí derogó expresamente la incapacidad relativa de la mujer casada al modificar el artículo 55 del Código Civil Argentino. Otra pieza normativa que implicó una evolución positiva en la equiparación de los derechos de la mujer fue la ley 23.264 que equilibró la situación de la mujer en los siguientes aspectos: ejercicio de la patria potestad; elección del nombre de los hijos y ejercicio de la curatela de sus hijos. La ley 23.515 de Matrimonio Civil modificó la situación de la mujer casada en cuanto a su domicilio y en lo referido a su nombre.

Las llamadas incapacidades de derecho no pueden ser consideradas verdaderas incapacidades, sino prohibiciones de ejercer determinados actos, ya sea por sí mismo o por medio de un representante. Ejemplo de lo anterior fueron la prohibición contenida en el Código de Comercio derogado que excluía del ejercicio del comercio a los clérigos (mientras vistieran el traje clerical); a los magistrados civiles y jueces del territorio donde ejercieran su autoridad y jurisdicción con título permanente; a los interdictos y a los quebrados. Otro ejemplo de prohibiciones interesantes son las contenidas en el Código Electoral (Ley 19945), que excluía del padrón electoral a los dementes declarados en juicio y a quienes estuvieran recluidos en establecimientos públicos; los sordomudos que no supieran darse a entender por escrito; los condenados por delitos dolosos a penas privativas de la libertad y por sentencia ejecutoria en los términos de la condena; los condenados por juegos prohibidos; los sancionados por la infracción de deserción calificada los rebeldes en causas penales y otras tantas 
exclusiones. Para cerrar esta lista meramente ejemplificativa, merece agregarse la ley 26.370 de Espectáculos Públicos que, entre otros casos, prohíbe desempeñarse como trabajador de la actividad a aquellas personas que se hallen en alguna de las siguientes situaciones: haber sido condenadas por delitos de lesa humanidad; ser personal de las fuerzas armadas, de seguridad, policiales, del servicio penitenciario u organismo de inteligencia y haber sido condenado por delitos cometidos en el desempeño de la actividad regulada por esta ley.

\section{EL SISTEMA DEL CÓDIGO CIVIL Y COMERCIAL DE LA NACIÓN}

\section{EL ÁMBITO INTERNO. UN CAMBIO DE RUMBO. LA INCAPACIDAD POR INMADUREZ}

El sistema de la incapacidad de los menores en el Código Civil y Comercial "se sostiene sobre las ideas de capacidad progresiva y reconocimiento de la autonomía personal en función del estándar grado de madurez suficiente, amén del principio cardinal del superior interés del niño." ${ }^{6}$ Sin embargo, tal como señala Rivera, la madurez suficiente solo habilita el ejercicio de derechos por parte de un menor de edad para los casos que le son permitidos por el ordenamiento, y ello al tomarse conjuntamente lo dispuesto por el art. $24 \mathrm{y}$ el segundo párrafo del art. 26. Por lo que el régimen es bastante parecido al de la ley 17.711.

El paradigma del Código Civil y Comercial Argentino implica el paso de un sistema de capacidad rígido a un sistema de capacidad con mayor flexibilidad, que pondera circunstancias de hecho particulares, tiene origen constitucional y remite en última instancia a la inclusión de los tratados de derechos humanos que hoy forman parte del bloque de constitucionalidad que nos rige y que ha colocado al hombre en cuanto tal en primer plano del ordenamiento jurídico. ${ }^{7}$

$6 \quad$ Julio C Rivera, "Capacidad de las personas menores de edad en el Código Civil y Comercial de la República Argentina. Perplejidades e incongruencias", en Tratado de la Vulnerabilidad ed. por Ursula C Basset, Hugues Fulchiron, y otros, (Buenos Aires: La Ley, 2017), 295.

Mariana Santi, en Código Civily Comercial de la Nación y normas complementarias A1, ed. por Alberto J. Bueres, (Buenos Aires: Hammurabi, Buenos Aires, 2014), 275. 


\section{LA INCAPACIDAD POR AFECTACIÓN DE LA VOLUNTAD O DEL ENTENDIMIENTO}

En primer lugar, se debe advertir al tratar este tema que, conforme a la normativa del art. 32 Código Civil y Comercial, ${ }^{8}$ se entiende como principio general la restricción dirigida al ejercicio de la capacidad, y de manera excepcional la declaración de incapacidad; siendo que en el título de dicho artículo se diferencian dos supuestos claramente evidenciados: la

\section{persona con capacidad restringida y la persona incapaz.}

En cuanto al primer supuesto (restricción a la capacidad) se observa que para que proceda debe referirse a personas mayores a trece años - estableciéndose asi un piso objetivo de aplicación concordante con la categoría de adolescente dispuesta en el Art. 25 del mismo instrumento - que padezcan adicciones o alteraciones mentales permanentes o prolongadas, de suficiente gravedad, y siempre que se estime que de dicha limitación mental y en relación al ejercicio de su capacidad pueda resultar un daño para su persona o bienes. A su vez, se identifica que la norma importa un contenido genérico en cuanto al espectro de las personas afectadas; es decir personas que contengan adicciones o alteraciones mentales, eliminando todo tipo de etiquetas conceptuales que establecía la normativa anterior.

Por otra parte, conforme al segundo párrafo de la norma aquí analizada, el juez debe designar el o los apoyos necesarios que prevé el art. $43^{\circ}$, especificando las funciones de éstos debido a las necesidades y circunstancias de cada persona, por lo que, en consecuencia, en este supuesto la figura del curador desaparece. Es así que, al conceptualizar los apoyos conforme a la normativa precitada resultan aquellas medidas de carácter judicial y extrajudicial que facilitan a la persona que las necesita la toma de decisiones respecto a administrar sus bienes, dirigir su persona y celebrar actos jurídicos en general. Por ende, estas medidas

\footnotetext{
8 Artículo 32: CCC: "Persona con capacidad restringida y con incapacidad. El juez puede restringir la capacidad para determinados actos de una persona mayor de trece ańos que padece una adicción o una alteración mental permanente o prolongada, de suficiente gravedad, siempre que estime que del ejercicio de su plena capacidad puede resultar un dańo a su persona o a sus bienes. En relación con dichos actos, el juez debe designar el o los apoyos necesarios que prevé el artículo 43, especificando las funciones con los ajustes razonables en función de las necesidades y circunstancias de la persona. El o los apoyos designados deben promover la autonomía y favorecer las decisiones que respondan a las preferencias de la persona protegida. Por excepción, cuando la persona se encuentre absolutamente imposibilitada de interaccionar con su entorno y expresar su voluntad por cualquier modo, medio o formato adecuado y el sistema de apoyos resulte ineficaz, el juez puede declarar la incapacidad y designar un curador."

9 . Artículo 43, CCC "Concepto. Función. Designación. Se entiende por apoyo cualquier medida de carácter judicial o extrajudicial que facilite a la persona que lo necesite la toma de decisiones para dirigir su persona, administrar sus bienes y celebrar actos jurídicos en general. Las medidas de apoyo tienen como función la de promover la autonomía y facilitar la comunicación, la comprensión y la manifestación de voluntad de la persona para el ejercicio de sus derechos. El interesado puede proponer al juez la designación de una o más personas de su confianza para que le presten apoyo. El juez debe evaluar los alcances de la designación y procurar la protección de la persona respecto de eventuales conflictos de intereses o influencia indebida. La resolución debe establecer la condición y la calidad de las medidas de apoyo y, de ser necesario, ser inscripta en el Registro de Estado Civil y Capacidad de las Personas."
} 
tendientes a que se promueva la autonomía del individuo afectado por la restricción a la capacidad establecen un canal específico para la expresión de su voluntad.

Para culminar con el análisis del presente supuesto, se debe notar que "el o los apoyos" pueden recaer sobre una persona (o varias) propuesta por el interesado. No obstante ello, es el Juez quien debe decidir respecto a la designación, evaluando y estableciendo un sistema de actuación por parte de las personas que resultasen designadas para cumplir las medidas a los efectos de evitar conflictos o influencias que puedan resultar en perjuicio del sujeto.

Ahora bien, respecto del segundo supuesto, la incapacidad absoluta, contemplado en el último párrafo del art.32, el mismo prevé la incapacidad exclusivamente para aquellos casos en los que la persona esté completamente imposibilitada de interactuar con su entorno social, resultando imposible la determinación de la expresión de su voluntad por cualquier medio de reproducción y que a su vez el sistema de apoyos sea ineficaz. En este supuesto el juez puede declarar la incapacidad y designar un curador que se regirá por las reglas de la curatela (Arts. 138 CCC y ccdts.).

Nótese que la norma señala el carácter excepcional de la declaración de incapacidad, identificándose además que la misma procede cuando no exista posibilidad de interrelacionarse e interactuar con el entorno social, pero además que el sistema de apoyos no resulte efectivo; es decir que, dada la disyunción "y”, deben cumplirse ambos supuestos y no resultar situaciones independientes (o que la persona no pueda interactuar con el entorno o bien que el sistema de apoyos resulte eficaz). Nuevamente se está bajo el manto de un criterio protector de la autonomía de la voluntad de la persona.

Así las cosas, el criterio mencionado fue introducido primeramente en el Código Civil Argentino, a través de la Ley 26.657 - Ley Nacional de Salud Mental, el cual introdujo el Art. 152 ter, disponiendo: “Las declaraciones judiciales de inhabilitación o incapacidad deberán fundarse en un examen de facultativos conformado por evaluaciones interdisciplinarias. No podrán extenderse por más de TRES (3) ańos y deberán especificar las funciones y actos que se limitan, procurando que la afectación de la autonomía personal sea la menor posible."

En dicha norma se observa el pilar fundamental de la autonomía personal y su menor restricción posible. Es decir, se abandonó el criterio de persona incapaz o persona capaz entrando en un matiz de grises y de comprensión de situaciones excepcionales y particulares.

La capacidad general de ejercicio se presume, aún cuando una persona se encuentre internada en un establecimiento asistencial. Las limitaciones son de carácter excepcional y se las debe declarar judicialmente si existe una afectación de la voluntad por adicción o una 
alteración mental permanente o prolongada que implique un daño para la persona o sus bienes. Al limitar la capacidad de una persona se deben designar apoyos de modo que se promueva la autonomía de la misma. Por excepción el juez puede declarar la incapacidad y designar un curador (art. 31 y 31 del CCC).

\section{FUENTES DEL SISTEMA DE INCAPACIDAD DEL CÓDIGO CIVIL Y COMERCIAL}

Puede citarse como fuente del sistema de capacidad argentino a la Constitución Nacional reformada en 1994, en cuanto al reconocimiento de la jerarquía de los tratados internacionales que están por encima de las leyes y a la constitucionalización de los tratados de derechos humanos con el mecanismo previsto en el artículo 75, inciso 22 de la Constitución Argentina.

Uno de dichos tratados que posee en Argentina rango constitucional es la Convención sobre los Derechos de las Personas con Discapacidad (CDPD), adoptada por la Asamblea General de las Naciones Unidas en diciembre de 2006, que fuera ratificada con la promulgación de la ley 26.378 el día 6 de junio de 2008. Esta convención es considerada como fuente del nuevo sistema de incapacidad prevista en el Código Civil y Comercial de la Nación.

La CDPD transformó el enfoque adoptado por el derecho internacional de los derechos humanos para garantizar la igualdad de derechos de las personas con discapacidad. Retiró el enfoque de estereotipos de larga data que consideraban que el "problema” radicaba en el impedimento de una persona, y lo dirigió a las barreras "discapacitantes" que la sociedad levanta y su responsabilidad de derribarlas y acomodar las necesidades de las personas con discapacidades. Requiere que todas las personas sean consideradas como capaces de tomar sus propias decisiones, con apoyos si es necesario, y con derecho a participar en los asuntos que las afecten.

La Argentina, como todos los países firmantes, se comprometió a elaborar y poner en práctica políticas, leyes y medidas administrativas para asegurar los derechos reconocidos en la Convención y abolir las leyes, reglamentos, costumbres y prácticas que constituyen discriminación. En este sentido, esta Convención puede considerarse como una fuente del tratamiento de la incapacidad en el Código Civil y Comercial de la Nación, en particular en lo que establece en su art. 12 sobre las salvaguardas previstas para que "el ejercicio de la 
capacidad jurídica respete los derechos, la voluntad y las preferencias de la persona, que no haya conflicto de intereses ni influencia indebida, que sean proporcionales y adaptadas a las circunstancias de la persona, que se apliquen en el plazo más corto posible y que estén sujetas a exámenes periódicos por parte de una autoridad o un órgano judicial competente, independiente e imparcial. Las salvaguardias serán proporcionales al grado en que dichas medidas afecten a los derechos e intereses de las personas." Este criterio parece ser atendido por el sistema del Código Civil y Comercial, aunque el documento denominado "Observaciones finales" sobre la Argentina, aprobado por el Comité de Seguimiento de los Derechos de las Personas con Discapacidad de las Naciones Unidas en su octava sesión, sostiene que:

el Comité está profundamente preocupado por las inconsistencias que se observan tanto en las leyes existentes como en los proyectos actualmente en consideración por el Estado parte (la Argentina), que se basan o continúan basándose en un modelo de sustitución del proceso de toma decisiones que anula los deseos de la persona en cuestión, claramente contradiciendo el art. 12 de la Convención. ${ }^{10}$

El Comité urge a la Argentina a eliminar el proceso de sustitución por el de apoyos, (cuestión esta sí atendida por el nuevo código argentino) y eliminar la discreción de los jueces para decidir sobre los apoyos que puede necesitar una persona. Expresamente solicita que el concepto de incapacidad no sea incluido en el proyecto de Código Civil y Comercial. Estas recomendaciones no fueron totalmente atendidas, ya que el contenido normativo del Art. 32 del Código establece que "El juez puede restringir la capacidad para determinados actos de una persona mayor de trece años que padece una adicción o una alteración mental permanente o prolongada, de suficiente gravedad, siempre que estime que del ejercicio de su plena capacidad puede resultar un daño a su persona o a sus bienes”. En relación con dichos actos, el juez debe designar el o los apoyos necesarios que prevé el artículo 43, especificando las funciones con los ajustes razonables en función de las necesidades y circunstancias de la persona. El o los apoyos designados deben promover la autonomía y favorecer las decisiones que respondan a las preferencias de la persona protegida. Por excepción, cuando la persona se encuentre absolutamente imposibilitada de interaccionar con su entorno y expresar su voluntad por cualquier modo, medio o formato adecuado y el sistema de apoyos resulte ineficaz, el juez puede declarar la incapacidad y designar un curador.

10 UN Committee on the Rights of Persons with Disabilities (CRPD), Concluding observations on the initial report of Argentina as approved by the Committee at its 8th session, 17-28 September 2012: Committee on the Rights of Persons with Disabilities, 8 October 2012, CRPD/C/ARG/CO/1, available at: http://www.refworld.org/docid/54993c374. html [accessed 6 November 2017]. 
Se destaca que la Convención sobre los Derechos de las Personas con Discapacidad resulta el andamiaje normativo que ha utilizado el Estado argentino, el cual fuera destinado al desarrollo de la autonomía de los individuos con discapacidades; a lo que podemos sumar, los que se refieren a los diversos temas siguientes: Igualdad y no discriminación (Art.5), el cual establece que los Estados Partes deben reconocer la igualdad de todos los ciudadanos, prohibiendo las prácticas que fomenten discriminación por motivos de discapacidad; Toma de Conciencia (Art. 8), el cual establece que los Estados Partes deben tomar medidas de sensibilización, movilización, promoción y lucha contra la discriminación, con miras a la inclusión social; Accesibilidad (Art. 9), el cual establece la toma de medidas tendientes a que las personas con discapacidad puedan vivir en forma independiente y participar plenamente en todos los aspectos de la vida; Acceso a la Justicia (Art. 13), referido a las medidas tendientes para que las personas con discapacidad tengan acceso a la justicia en igualdad de condiciones con las demás, incluso mediante ajustes de procedimiento y adecuados a la edad, para facilitar el desempeño de las funciones efectivas y que las personas con discapacidad tengan acceso efectivo a la justicia.

Por otra parte, y en relación con la libertad de desarrollo individual, que puede vincularse claramente con los apoyos, debemos destacar el Art. 19 de la Convención sumamente interesante que establece:

Los Estados Partes en la presente Convención reconocen el derecho en igualdad de condiciones de todas las personas con discapacidad a vivir en la comunidad, con opciones iguales a las de las demás, y adoptarán medidas efectivas y pertinentes para facilitar el pleno goce de este derecho por las personas con discapacidad y su plena inclusión y participación en la comunidad, asegurando en especial que: a) Las personas con discapacidad tengan la oportunidad de elegir su lugar de residencia y dónde y con quién vivir, en igualdad de condiciones con las demás, y no se vean obligadas a vivir con arreglo a un sistema de vida específico; b) Las personas con discapacidad tengan acceso a una variedad de servicios de asistencia domiciliaria, residencial y otros servicios de apoyo de la comunidad, incluida la asistencia personal que sea necesaria para facilitar su existencia y su inclusión en la comunidad y para evitar su aislamiento o separación de ésta; c) Las instalaciones y los servicios comunitarios para la población en general estén a disposición, en igualdad de condiciones, de las personas con discapacidad y tengan en cuenta sus necesidades.

Si bien la CDPD es la fuente del tratamiento de la discapacidad, y representa una evolución favorable en la eliminación de barreras sociales, políticas y jurídicas injustas, el instituto de la incapacidad es la protección que el sistema jurídico prevé para aquellas personas que por falta de madurez suficiente o por afectación en su voluntad o entendimiento no pue- 
den ejercer por si mismas sus derechos o realizar actos jurídicos. Se establece para proteger al incapaz y evitar que realice actos que pudieran perjudicarle. La finalidad del instituto de la incapacidad no es la seguridad jurídica sino la protección de la persona. Esta protección se ejerce dándole una representación.

\section{OTRAS FUENTES DEL SISTEMA DE INCAPACIDAD}

También es fuente del nuevo régimen la Ley 26.061 de Protección Integral de Niños, Niñas y Adolescentes de 1995, que incorpora al sistema jurídico argentino el derecho de los menores a ser oídos ante la autoridad competente, a que su opinión sea tomada prioritariamente en cuenta a la hora de arribar a una decisión que los afecte, a ser asistidos por un letrado especializado, a participar activamente en todo procedimiento que los involucre y a recurrir ante el superior frente a una decisión que los afecte. Esta ley también incorporó el estándar de grado de madurez suficiente y el de capacidad de discernimiento. Rivera señala que la capacidad progresiva ya estaba presente en el Código de Vélez de 1869 donde, si bien en lo referido a lo patrimonial, numerosas reglas atribuían capacidad a los menores para ciertos actos.

Las leyes 26.743 de Identidad de Género; 25.673 del Programa Nacional de Salud y Procreación Responsable; 26.150 del Programa Nacional de Educación Sexual Integral y la Ley 418 de Salud Reproductiva de la Ciudad Autónoma de Buenos Aires también incluyen el principio de capacidad progresiva, por lo que constituyen fuentes del sistema del Código Civil y Comercial, y por su lado la Ley 26.529 de Derechos del Paciente también incluye el principio de autonomía de la persona en general y el de capacidad progresiva de los menores.

Es indiscutible que el derecho argentino ha tenido una notable y auspiciosa evolución a partir de 1990, incorporando los principios de interés superior del niño, capacidad progresiva, derecho del niño a ser oído en todo aquello que le concierna y el estándar grado de madurez suficiente." 11

La Ley 26.657 de Salud Mental constituye sin duda también una fuente importante del sistema de incapacidad actual, ya que reconoce a la salud mental como un proceso determinado por componentes históricos, socioeconómicos, culturales, biológicos y psicológicos, cuya preservación y mejoramiento implican una dinámica de construcción social vinculada

11 Rivera, Capacidad, 298. 
a la concreción de los derechos humanos y sociales de toda persona. Por ende, es necesario partir de la presunción de capacidad de todas las personas. Esta misma ley también legisla sobre el tratamiento de adicciones e impide que el diagnóstico en el campo de la salud mental haga presumir riesgo de daño o incapacidad.

Se reconoce a las personas con padecimiento mental entre otros, el derecho a recibir tratamiento y a ser tratado con la alternativa terapéutica más conveniente, y que menos restrinja sus derechos y libertades, promoviendo la integración familiar, laboral y comunitaria; el derecho a ser informado de manera adecuada y comprensible sobre los derechos que lo asisten; el derecho a poder tomar decisiones relacionadas con su atención y su tratamiento dentro de sus posibilidades y el derecho a que el padecimiento mental no sea considerado un estado inmodificable. Todo estos, criterios fueron incorporados en el sistema del Código Civil y Comercial.

\section{PROYECCIÓN DE LAS CAUSALES DE INCAPACIDAD}

El profesor Marcos M. Córdoba ha trabajado el tema de la capacidad infantil, cuestionando las teorías de las etapas evolutivas del niño del tipo de las descriptas por Piaget, tendientes a enfatizar la idea de un déficit de la infancia y, según ellas, entendiendo la naturaleza del principalmente como resultante de capacidades faltantes en ellos respecto de las de los adultos. Esta concepción, argumenta Córdoba, ignora o subestima el hecho de que los niños son, por ejemplo, más capaces de aprender un segundo idioma, pintar una imagen estéticamente valiosa o concebir una pregunta filosóficamente interesante que esos mismos niños que cuando lleguen a ser adultos probablemente sean incapaces de realizar. "De esa "incompletud" del nińo se causa su carencia de responsabilidad, lo que implica incapacidad de reconocer y aceptar en extensión completa las consecuencias de sus actos. Es esa falta de responsabilidad lo que habilita los desempeños espontáneos, los juegos, lo que se hace como ejercicio no sometido a reglas sino de un modo de proceder sin consecuencias ni formalidad, desempeños que desarrollan la facultad creativa, la introducción de elementos originales en el conjunto de su contenido intelectual. De lo dicho resulta que las causas de vulnerabilidad que afectan al niño son causa como contrapartida de una circunstancia que le resulta favorable en otros aspectos no sometidos a su protección. Es que el niño es persona que, por no haber completado su desarrollo, la ley protege al no habilitarlo a despeńarse por sí mismo y 
a título propio, porque lo contrario lo pone en condiciones de mayor vulnerabilidad, lo hace apto para ser dańado, menoscabado, echado a perder." ${ }^{2}$

Lo mismo sucede con los adultos mayores, quienes manifiestan ciertas limitaciones en sus capacidades propias de su edad. Sus carencias también muchas veces los habilitan a desarrollar otras potencialidades, que deben valorarse positivamente. Por el contrario, se nota una tendencia a intentar alterar el estado natural de la persona mayor, dándole medicamentos que los mantienen artificialmente en un estado diferente al que naturalmente les corresponde.

Así, la tendencia que se observa en la evolución del concepto de incapacidad exacerba la autonomía del individuo. Se busca dotar a los menores de la mayor autonomía posible, cuanto antes, aún aquella que los saca de su condición de niños. Se toman medidas para que los adultos mayores también mantengan su autonomía, aún más allá de las restricciones propias de su edad. En esta tendencia se advierte una sociedad y una concepción del derecho individualista, que no cuenta con el criterio de solidaridad jurídica. El Principio General de la Solidaridad Legal, que constituye un estándar moral de la sociedad, requiere necesariamente ponerse en el lugar del otro, ejercer los propios derechos considerando también el interés del otro. Este principio es de tal importancia que su aplicación transforma el ejercicio del derecho radicalmente, alejando a la sociedad del sistema incoherente, individualista e injusto que considera a cada persona como aislada o autónoma. ${ }^{13}$

Dar autonomía al niño antes de lo necesario o prolongar la autonomía de las personas en momentos de afectación de su voluntad o entendimiento desconoce la posibilidad de una sociedad en la que la persona forma parte de una comunidad solidaria. La CDPD constituye un esfuerzo legítimo para la eliminación de todo tipo de discriminación contra las personas con discapacidad, pero el instituto de la incapacidad responde a una necesidad diferente, que busca proteger a la persona, permitiéndole que cumpla su ciclo de vida vital sin interferencias artificiales, contando con la solidaridad de sus semejantes.

Como un estándar moral, producido por el conjunto de la sociedad, se sostiene que el principio de solidaridad debe constituirse como principio general del derecho positivo argentino y consecuentemente ser atendido por el legislador, para informar a la ley, y por el

12 Marcos M. Córdoba, "Protección del niño vs. Autonomía del niño", en Tratado de la Vulnerabilidad, ed. por Ursula C Basset, Hugues Fulchiron, y otros, (Buenos Aires: La Ley, 2017), 401.

13 Para un análisis completo del Principio de Solidaridad Jurídica ver Alejandro Laje, "La solidaridad familiar como paradigma de la solidaridad en los sistemas jurídicos occidentales", en Derecho Moderno, (Buenos Aires: Editorial Rubinzal Culzoni, 2014) y Alejandro Laje, "El principio general de solidaridad en el Derecho Argentino" El Derecho, Buenos Aires, 1 de abril (2016). 
juez para aplicarla. Del mismo modo y fundamentalmente debe ser considerado por cada persona al momento de interpretar el derecho vigente.

Dicha elevación positiva del principio de solidaridad no se ha producido aun, ya que, si bien el principio de solidaridad está presente en numerosas normas particulares, no ha sido positivizado aun como un principio general del derecho argentino. Puntualmente, en lo que refiere al instituto de la incapacidad, su eventual eliminación del sistema argentino implicaría un retroceso en la evolución hacia un derecho más solidario.

La solidaridad jurídica, como principio general social consiste en una noción que no resulta de una elaboración de científicos sino de la expresión social. Siendo esos valores elementos que informan al derecho, el legislador los interpreta y transfiere al ámbito legislativo. Habitualmente como consecuencia de la información que la doctrina especializada le ha proporcionado. Su incorporación a la ley puede producirse a través de normas particulares o de aquellas denominadas generales o abiertas. La información al legislador puede arribar al estándar de la ley ordinaria o incluso al más elevado que es el constitucional y es ahí donde como consecuencia la ley ordinaria puede buscar los principios no solo en la doctrina y en el comportamiento social sino también en eso que se ha convertido en principio constitucional.

Ciertamente la solidaridad es un importante criterio que está en el fundamento de numerosas soluciones legislativas y seguramente constituye una directriz y un instrumento de la interpretación para casos dudosos o lagunas que se presentan en la regulación de la vida social. Privar al derecho argentino del instituto de la incapacidad implicaría debilitado y empobrecido por privarlo de una norma que se apoye en la solidaridad como principio general del derecho.

En contra de este criterio, se podría afirmar que la solidaridad no constituye un estándar moral de la sociedad argentina, sino que a nuestra sociedad está caracterizada por la tendencia al individualismo y la búsqueda egoísta de fines estrictamente personales. Esta postura resulta objetable ya que, si bien pueden encontrarse dichas conductas en numerosas circunstancias de la vida nacional, constituyen discontinuidades en una continuidad histórica de discursos y prácticas cualitativamente distintas presentes en las aspiraciones de la sociedad en su conjunto.

Ello debido a que la solidaridad se define como la relación recíproca entre el todo y sus partes. Ningún problema pertenece solo a una persona y se debe rechazar la idea de que la mente está primero sola, y luego en relación con otros ya que la conciencia de uno mismo, como yo y como persona, es siempre experimentada en el contexto de su membresía a una totalidad. Se distingue el principio de solidaridad del de simple agregación presente 
en las relaciones sociales. La sociedad solidaria no tiene nada que ver con aquella que está simplemente junta. Es posible aspirar a una sociedad solidaria en la que sus miembros están unidos según la cualidad de su participación en el grupo, diferenciándola de las sociedades estructuradas en la búsqueda de la mayor felicidad individual o del mayor número.

Así, si no se logra establecer la diferencia entre discapacidad e incapacidad, es posible que la proyección de las causales de incapacidad evolucione hacia un estado de mayor autonomía de los niños y a la prolongación artificial de la autonomía de quienes tienen afectada su voluntad o entendimiento. Sin embargo, si se comprende la protección que brinda la incapacidad, se habilitará el camino para el ejercicio de la solidaridad jurídica.

\section{CONCLUSIÓN}

La idea de persona como centro de todo el sistema jurídico encuentra su fuente en el Derecho Romano. Su evolución hasta llegar al concepto actual ha requerido el aporte de generaciones de juristas preocupados por dotar al sistema jurídico de las herramientas que permitan darle a la persona física toda la dignidad de seres valiosos en sí mismos. La capacidad de la persona refleja la dignidad de quien se autodetermina, manifestando solo uno de los aspectos de su dignidad. Ello en el contexto propio del dinamismo de los elementos culturales, los cuales creados por el hombre van adecuándose a los contextos socio-históricos.

Tal como se afirmó oportunamente, el derecho argentino en la Constitución Nacional, los tratados internacionales, la normativa específica del Código Civil y Comercial de la Nación y otras leyes particulares colocan a la persona humana en el centro de la consideración jurídica. Así, debe resaltarse que los institutos de la capacidad y de la incapacidad han evolucionado en consecuencia en la búsqueda de idéntico objetivo, implicando ello la habilitación que recibe toda persona para ejercer ciertos roles y capacidades en la sociedad, destacando claramente aquella idea expresada ut-supra: “... Ser persona requiere decir ser reconocido por los demás en dicho rol y capacidad..." Se advierte que, en la idea actual de persona, como sujeto de derecho, convergen ideas metafísicas y jurídicas, remitiendo a la noción de intersubjetividad.

El tratamiento de la incapacidad en el ordenamiento jurídico argentino fue modificado desde su concepción original por leyes tales como la Ley 17.711, Ley 11.357, Ley 23.264, Ley 23.515, Ley 19.945, mencionadas oportunamente. 
Ahora bien, en la reciente modificación introducida en el Código Civil y Comercial de la Nación se advierte un cambio - nuevamente - el cual pretende ser protectorio, toda vez que invierte los principios generales y especiales en materia de capacidad, otorgando al primero de ellos, la restricción dirigida al ejercicio de la capacidad, sin incorporar mecanismos de sustitución de la persona, mientras que la excepcionalidad encuentra en la incapacidad del sujeto.

En ese camino frecuentemente se pierde de vista que el instituto de la incapacidad siempre fue establecido en protección de la persona vulnerable por lo que resulta inconsistente intentar su eliminación, por más bien intencionado que parezca.

A la persona menor, la ley la protege por no haber completado su desarrollo, no habilitándolo a desempeñarse por sí mismo y a título propio. Lo contrario sería colocarla en situaciones de mayor vulnerabilidad. Se sostiene aquí que algunos adultos mayores, están en una situación semejante ya que dadas las limitaciones propias de la etapa etaria que transitan, y las respectivas carencias de salud - de indole física o mental. Se advierte la tendencia a alterar fisiológicamente dichas carencias, para mantener un estado de capacidad "superficial" o "irreal"; es decir, diferente al que les correspondería. Concluyendo así, que se advierte un andamiaje evolutivo en materia del desarrollo de la capacidad que exacerba la necesidad de desarrollar la autonomía del individuo, poniendo a niños o adultos, en una situación ficticia, y disponiéndoles en un posicionamiento que, en casos no sea el adecuado.

Por ello, se sostiene que la implementación de los institutos de la capacidad y de la incapacidad debe ser aplicada teniendo presente el principio de solidaridad legal para que pueda cumplir con todo el alcance de su efecto protectorio; en miras de la salvaguarda real de los intereses de los sujetos de derechos tutelados; toda vez que éste principio importa un estándar por el que se requiere el ejercicio de los derechos considerando también el interés del otro, resultando así que su aplicación transforma la construcción de los institutos de la capacidad y de la incapacidad.

Para citar este artículo: Laje, Alejandro y Gabriel Lanzavechia: "Fuentes y proyección de las causales de incapacidad”, https://doi.org/10.22235/rd.v0i17.1520 Revista de Derecho $\mathrm{N}^{\circ} 17$ (julio 2018), ISSN 1510-3714, ISSN On line 2393-6193: 65-84. 


\section{BIBLIOGRAFÍA}

Alchourrón, Carlos y Eugenio Bulygin, Introducción a la metodología de las ciencias jurídicas y sociales, Buenos Aires: Astrea, 2006.

Alexy, Robert, Teoría de los Derechos Fundamentales, Madrid: Centro de Estudios Políticos y Constitucionales, 2002.

Alpa, Guido, "La certeza del Derecho en la edad de la incertidumbre”, La ley, 2006-B.

Alpa, Guido, "Privacy e estatuto dell informatione", Rivista di Diritto Civile, n. 1, 1979.

Arendt, Hannah, La condición humana, Buenos Aires: Paidós, 2005.

Berlin, Isaiah, Vico y Herder. Dos estudios de la historia de las ideas, Madrid: Cátedra, 2000.

Berlin, Isaías, Dos conceptos de libertad y otros escritos, Madrid: Alianza, 2005.

Bueres, Alberto J. y Elena Highton, Código Civil y normas complementarias, 1A, Buenos Aires: Hammurabi, 2007.

Cárcova, Carlos María, La Opacidad del Derecho, Madrid: Trotta, 2006.

Cárcova, Carlos María, Las Teorías Jurídicas Post Positivistas, Lexis Nexis, Buenos Aires 2007.

Córdoba, Alfredo del C. M., Derecho Civil. Parte General, Buenos Aires: Biblioteca de la Universidad Abierta Interamericana, 2017.

Córdoba, Marcos M. “Actualidad del Derecho de Familia”, conferencia, Instituto de Derecho de Familia del Colegio Público de Abogados, Buenos Aires, 2 de octubre de 2017.

Córdoba, Marcos M., "Protección del niño vs. Autonomía del niño", en Tratado de la Vulnerabilidad, ed. por Ursula C Basset, Hugues Fulchiron, y otros, Buenos Aires: La Ley, 2017.

Choza, Jacinto, Filosofía del Hombre, Madrid: Ediciones RIALP, 1993.

Dewey, John, La miseria de la epistemología. Ensayos de Pragmatismo, Madrid: Biblioteca Nueva, 2000.

Dworkin, Ronald, Los Derechos en serio, Barcelona: Ariel, 2002.

Gallo, Institutas, Commentarius Primus III. http://fama2.us.es/fde/ocr/2006/institutaDeGayo.pdf, 1.2.2018.

Gelli, María Angélica, Constitución de la Nación Argentina. Comentada y Concordada, Buenos Aires: La Ley, 2005.

Habermas, Jürgens, El Discurso Filosófico de la Modernidad, Mostroles-Madrid: Katz, 2013. Kitto, H. D. F., Los Griegos, Buenos Aires: Eudeba, 1977. 
Laje, Alejandro, "El principio general de solidaridad en el Derecho Argentino" El Derecho, Buenos Aires, 1 de abril (2016).

Laje, Alejandro, "La solidaridad familiar como paradigma de la solidaridad en los sistemas jurídicos occidentales", en Derecho Moderno, Buenos Aires: Editorial Rubinzal Culzoni, 2014.

Llambías, Jorge, Tratado de Derecho Civil: Parte General, Buenos Aires: Abeledo - Perrot , 2003.

Negri, Héctor, Sobre el Derecho y los Derechos del Hombre, Buenos Aires: Lexis Nexis Abeledo Perrot, 2008.

Orgaz, Alfredo, Personas Individuales, Buenos Aires: Assandri, 1961.

Rivera, Julio C. "Capacidad de las personas menores de edad en el Código Civil y Comercial de la República Argentina. Perplejidades e incongruencias", en Tratado de la Vulnerabilidad ed. por Ursula C Basset, Hugues Fulchiron, y otros, Buenos Aires: La Ley, 2017.

Rorty, Richard, Philosophy and the Mirror of Nature, Princeton: Princeton University Press, 2009.

Santi, Mariana, "Comentario al Artículo" en Código Civil y Comercial de la Nación y normas complementarias A1, ed. Por Alberto J. Bueres, Buenos Aires: Hammurabi, Buenos Aires, 2014.

Sibila, Paula, La intimidad como espectáculo, Buenos Aires: FCE, 2009.

Tobías, José W , “La persona humana en el proyecto”, La Ley, 25/06/2012.

Vattimo Gianni, El fin de la modernidad, México: Gedisa Editorial, 2000. 